Paidéia, 2006, 16(35), 305-313

\title{
O SOCIODRAMA COMO MÉTODO DE PESQUISA QUALITATIVA ${ }^{1}$
}

\author{
Maria da Penha Nery \\ Liana Fortunato Costa ${ }^{2}$ \\ Maria Inês Gandolfo Conceição \\ Universidade de Brasília
}

Resumo: O objetivo deste texto foi propor o Sociodrama como método para a pesquisa qualitativa em Psicologia, de modo a propiciar a interação grupal como foco da investigação. Descreve-se a metodologia de intervenção sociopsicodramática, mostrando suas dificuldades tais como: planejamento da ação dramática, registro, observação, análise das informações e questões éticas. O Sociodrama pode ser opção para pesquisa ativa e construção de significações nas relações, num processo dialógico e compatível com pesquisas interventivas; busca-se ensejar reflexões que subsidiem o trabalho com grupos, e estabelecer uma ampliação sobre a micro-realidade social, considerando: a complexidade embutida nos relacionamentos afetivos, o potencial espontâneo do grupo.

Palavras-chave: Sociodrama; pesquisa qualitativa; método; pesquisa interventiva.

\section{SOCIODRAMA AS A QUALITATIVE RESEARCH METHOD}

Abstract: The objective of this text was to propose Sociodrama as a qualitative research method in Psychology, to enable the group interaction the focus of investigation. The methodology of sociopsychodramatic intervention is described, showing this method difficulties, as: dramatic action planing, registration, observation, information analysis and ethic matters. Sociodrama may be an active research and a relations meanings' construction, in a dialogic process and compatible with intervention researches; It is tried to generate a reflection that may bring subsidies to the work with groups, stablishing an enlargement over the social microreality, considering: the complexity built in the affective relations, releasing the spontaneous potential of the group.

Key words: Sociodrama; qualitative research; method; intervention research.

Este texto tem como objetivo apresentar, propor e defender o Sociodrama como um método para a pesquisa qualitativa em Psicologia Clínica, de modo a propiciar que a interação grupal seja o foco da investigação. Refere-se aqui à dinâmica afetiva relacional que caracteriza determinados grupos com intensa relação e que carecem de uma instrumentação adequada para a construção de um contexto favorável para que pesquisadores possam acessar as nuances grupais e individuais presentes nas relações grupais. Tomam-se como exemplo os grupos terapêuticos, os familiares e os comunitários. Para o objetivo da proposta utiliza-se o levantamento

\footnotetext{
${ }^{1}$ Recebido em 06/10/2006 e aceito para publicação em 18/01/2007.

${ }^{2}$ Endereço para correspondência: Liana Fortunato Costa, SQN 104 Bloco D - ap. 307, CEP: 70.733- 040, Brasília - DF,

E-mail: lianaf@terra.com.br
}

bibliográfico, aliado à experiência em pesquisa e em orientação com a teoria e metodologia de Jacob Levy Moreno.

\section{Sociodrama: método para o estudo do grupo}

O Sociodrama surgiu do Teatro Espontâneo, criado por Moreno, no início do século XX. Trata-se de um dos métodos sociátricos para pesquisar e tratar os grupos e as relações intergrupais, seus conflitos e sofrimentos. Fundamenta-se na epistemologia socionômica e tem o objetivo de superar a dicotomia da pesquisa quantitativa/qualitativa, ao privilegiar a participação dos sujeitos na situação. O sociodrama é um método de pesquisa interventiva, que busca compreender os processos grupais e intervir em uma de suas situações-problema, por meio da ação/ comunicação das pessoas. Segundo Moreno (1975): 
"O verdadeiro sujeito do sociodrama é o grupo .... Há conflitos nos quais estão envolvidos fatores coletivos ... supra-individuais ... e que têm que ser compreendidos e controlados por meios diferentes. ... pode-se, na forma de sociodrama, tanto explorar, como tratar, simultaneamente, os conflitos que surgem entre duas ordens culturais distintas e, ao mesmo tempo, pela mesma ação, empreender a mudança de atitude dos membros de uma cultura a respeito dos membros da outra" ( $p$. 413-415)

O pesquisador-terapeuta proporciona ao grupo, por meio de sua demanda ou do seu consentimento, um encontro para abordar os temas ou os conflitos que lhe são peculiares. Nesta experiência, procura viabilizar a expressão das pessoas e suas tentativas de resolução dos conflitos. Os procedimentos sociodramáticos enfatizam a vivência do drama, ou seja, a dramatização de cenas pelos participantes ou as interações de papéis sociais relativas ao sofrimento em questão. $\mathrm{O}$ efeito terapêutico surge da catarse de integração dos papéis sociais que são representados em ação dramática ou na interação grupal, realizada num espaço cênico. Entende-se por catarse de integração o fenômeno que possibilita a liberação de papéis cristalizados em impressões inadequadas e a conseqüente facilidade em assumir novas condutas (Menegazzo, Tomasini \& Zuretti, 1995).

No espaço para a ação, os papéis sociais tornam-se sociodramáticos, pois os atores vivem uma realidade suplementar propiciadora de um texto único, in status nascendi, criado conjuntamente. $\mathrm{Na}$ realidade suplementar, as interações são de um sujeito-protagonista e de sujeitos, autores e atores de suas vidas em reconstrução e em revisão; estes atualizam papéis que estão em estado potencial e encontram personagens espontâneos-criativos que expressam os estados co-conscientes e coinconscientes. $\mathrm{O}$ pesquisador-terapeuta tem como objetivo fundamental a co-criação que proporciona o bem-estar grupal e intergrupal. A encenação dos conflitos sociais e políticos leva as pessoas a co-criarem e a viverem a catarse de integração, numa perspectiva de entendimento e de desenvolvimento social.

Para Kellerman (1998), “A administração dos conflitos se transforma numa tarefa que é, no mínimo, tão importante quanto ajudar os sobreviventes a lidar com suas experiências traumáticas" (p. 52). O autor aponta o Sociodrama como um dos recursos do terapeuta de grupo para essa tarefa e apresenta três tipos de aplicações, que são: o Sociodrama da crise; o político e o da diversidade. O Sociodrama da crise tem o foco social sobre o trauma, a teoria social é a da adaptação e o ideal social é a homeostase. Buscase ajudar o grupo a melhor enfrentar as tensões sociopsicológicas e a encontrar novo equilíbrio social. O Sociodrama político tem o foco social sobre a desintegração, a teoria social é a do conflito e o ideal social a igualdade. Os temas são a desintegração social, a estratificação e a desigualdade como manifestações de conflitos socioeconômicos. Buscase impulsionar a sociedade na direção de maior justiça e eqüidade sociais. O Sociodrama da diversidade trabalha com conflitos advindos de estereótipos, preconceitos, racismo, intolerância, estigmatização e/ ou atitudes negativas contra pessoas de extratos minoritários. Busca-se respeitar as diferenças e transcendê-las quando se percebe que estas geram processos identitários que causam violência ou compartimentalizam a humanidade em grupos mutuamente exclusivos e isolados.

Em dois trabalhos, Marra e Costa (2004a; 2004b) propõem o Sociodrama como uma epistemologia e uma prática social voltada para uma abordagem grupal/comunitária, e como um método para a pesquisa-ação. Como práxis da Psicologia Comunitária, as autoras percebem o trabalho sociodramático como uma oportunidade para que todos influenciem e sejam influenciados mutuamente; e como um método viável para a pesquisa-ação, porque privilegia a dimensão relacional que está contida no Sociodrama, possibilitando a investigação sociológica dos sujeitos criadores da história.

A pesquisa-ação se fundamenta epistemologicamente, tal qual a Socionomia, nos grupos, nas comunidades e na dimensão relacional. Esta pesquisa, que surgiu da contribuição da teoria do campo de Lewin, privilegia a influência mútua dos participantes para as tomadas de decisões do grupo. Algumas das funções do pesquisador são: constatar o problema do grupo em crise; intervir para que a coletividade amplie seu conhecimento; e contribuir para a busca de 
resoluções. Barbier (2002) fala em uma açãopesquisa: "pesquisas utilizadas e concebidas como meio de favorecer mudanças intencionais" (p. 42); "O pesquisador intervém de modo quase militante no processo, em função de uma mudança cujos fins ele define como a estratégia" (p. 43). Segundo este autor, existe uma diversidade de tipos de pesquisa-ação que apontam para possibilidades de que estas dimensões de ação social e de pesquisa social possam estar em complementariedade. Neste sentido, enfocam-se os métodos sociátricos como coerentes e viáveis para uma ação que se desenvolve prioritariamente em grupos.

A pesquisa-ação tem suas origens após a Segunda Guerra Mundial com os trabalhos de Kurt Lewin que se pautavam em valores como a construção de relações democráticas; a participação dos sujeitos; o reconhecimento de direitos individuais, culturais e étnicos das minorias; a tolerância a opiniões divergentes; a consideração de que os sujeitos mudam mais facilmente quando influenciados por decisões grupais (Franco, 2005). O Sociodrama é, pois, uma metodologia de pesquisa ativa e traz, portanto, as significações presentes nas relações, o discurso compartilhado, e um processo dialógico com intensa troca de conteúdos psíquicos, atitudinais e comportamentais entre as pessoas, no propósito conjunto de solucionar deter-minados conflitos.

\section{Pesquisas e intervenções: revelando a prá- tica do Sociodrama}

Os sociodramas são realizados no mundo todo. Exemplos: Dalmiro Bustos dirigiu sociodramas na Argentina, durante a Guerra das Malvinas; Márcia Karp, na mesma época, realizou alguns na Inglaterra; Mônica Zuretti, na Alemanha, no período das eleições de extremistas de direita (Kellerman, 1998). No Brasil, em 2002, a Prefeitura da cidade de São Paulo, com a colaboração de Marisa Greeb, convidou psicodramatistas para realizar sociodramas, objetivando a participação dos cidadãos nas propostas de resoluções dos problemas encontrados. Esse foi um dos maiores eventos sociodramáticos do mundo (Cesarino, 2002). A Federação Brasileira de Psicodrama (FEBRAP), por intermédio de sua diretoria, busca se credenciar junto a entidades governamentais, como o Ministério da Saúde, para que os psicodramatistas participem de projetos ou os proponham em benefício da sociedade brasileira. A maioria das instituições de Psicodrama no Brasil, como a Associação Brasiliense de Psicodrama (ABP), oferece psicoterapia e sociodramas para a comunidade menos favorecida economicamente, em ações que têm uma proposição mais próxima com a Psicologia Comunitária.

Nos últimos 15 anos, as pesquisas sociodramáticas têm crescido no país. Destaca-se, por exemplo, Zampiere (1996) que realizou sociodramas construtivistas da Aids com casais heterossexuais, que favoreceram maior prevenção da doença nos chamados vínculos monogâmicos; e Seixas (1992) que privilegiou estudos sobre famílias, utilizando o método sociodramático sistêmico. A autora trouxe para o palco, por meio dos papéis familiares, os personagens e os conteúdos ocultos, que desintegram a família. Scaffi (2002) usou a metodologia sociodramática para prevenção da AIDS entre os indígenas, conseguiu ultrapassar as dificuldades de comunicação existentes entre membros de diferentes culturas e fortalecer a identidade indígena.

Desde 2002, sociodramas das cotas para negros nas universidades vêm sendo realizados sistematicamente pelas pesquisadoras Nery e Conceição $(2005,2006)$ com alunos da disciplina de Psicodrama do curso de Psicologia da Universidade de Brasília, com o objetivo de tratar, no coletivo, a polêmica instalada a partir da vigência da política afirmativa das cotas para negros nas universidades. Os resultados mostraram que a identificação de protagonistas do confronto coletivo mobiliza a cocriação, libera conteúdos cognitivos e emocionais dos estados co-consciente e co-inconsciente impeditivos da integração grupal e mobiliza a criação conjunta favorecedora do processo de inclusão social.

A partir de sua pesquisa realizada em 1998, Costa (2003) propôs e solidificou uma experiência realizada em uma comunidade de periferia com Grupos Multifamiliares que se constituiu numa contribuição para a Psicologia Clínica na Comunidade e que utilizou a metodologia psicodramática como referencial de ação e de investigação. Como produto da ação muitas mudanças foram detectadas, como a atualização do potencial criativo dos membros das 


\section{Maria da Penha Nery}

famílias, valorização do saber local, melhoria do processo comunicacional e de convivência. Da investigação foi possível fazer uma proposta de adaptação da sessão psicodramática e de aplicação desta metodologia para outros contextos de pesquisa, como o dos Grupos Multifamiliares em caso de abuso sexual (Costa, Penso \& Almeida, 2004; Costa, Penso, Legnani \& Antunes, 2005).

Conceição, Tomasello e Pereira (2003) realizaram estudos usando métodos sociátricos com adolescentes em medida socioeducativa de semiliberdade, indentificados pela justiça como usuários de drogas no Distrito Federal, visando a construção do projeto de vida, o resgate da auto-estima e a proteção, a partir de suas expressões artísticoculturais. Na mesma linha de ação e integrando o projeto, o Psicodrama foi apontado como fonte de construção de metodologia de intervenção com adolescentes, visando o questionamento com relação ao uso excessivo de drogas (Penso, Gusmão \& Ramos, 2003). Também, Ramos, Costa, Marra e Monteiro (1998) apontaram o contexto comunitário como bastante favorável para a pesquisa e intervenção em comunidade com a utilização do Psicodrama como método para os dois objetivos, e a Socionomia como viabilizadora da construção da cidadania.

Como exemplos de dissertações de Mestrado há Conceição (1994) e Marra (2003). Esta propôs o Sociodrama como o método para acessar as construções subjetivas e afetivas presentes nas relações entre famílias e agentes sociais do Conselho Tutelar; a primeira utilizou os métodos sociodramático e sociométrico (Conceição \& Sudbrack, 2004) para investigar os vínculos afetivos entre os membros de uma instituição alternativa para crianças em situação de rua, no intuito de desvendar os possíveis elementos que conduziam ao engajamento institucional de sua clientela. Com o trabalho de Marra (2003) foi possível clarificar o papel social dos conselheiros tutelares, verificar a responsabilidade das famílias na eficácia da intervenção social e refletir sobre a ampliação de redes sociais de apoio nas comunidades. Polejack e Costa (2003) fazem referência a uma pesquisa cujo objeto de estudo foi a avaliação da dinâmica conjugal de casais heterossexuais nos quais um cônjuge tinha o vírus HIV e o outro não. A proposta de avaliação foi realizada através da ação dramática, em mais um exemplo de utilização do Psicodrama como método de pesquisa. O que se depreende destes exemplos é que já está assentado no cenário da proposição metodológica uma aceitação do Psicodrama e do Sociodrama como caminhos favoráveis para uma orientação reducionista na escolha de um método para pesquisa com situações que envolvem grande complexidade social. Demo (1999) frisa que é fundamental colocar a realidade acima do método e não o contrário, não se podendo situá-la apenas no que cabe no escolhido.

\section{Acessando o grupo: os aspectos processuais do Sociodrama}

Em um ato sociodramático existem cinco elementos presentes (Moreno, 1974). O diretor é o pesquisador-terapeuta principal, responsável pela produção do evento. Os egos-auxiliares são os terapeutas treinados em Psicodrama que têm a função de contribuir para a explicitação do drama grupal, por meio de personagens ou participação nas técnicas solicitadas pelo diretor. O protagonista é o indivíduo que retrata e reflete o drama grupal, traz o conteúdo principal do sofrimento coletivo (também pode se apresentar na forma do tema grupal, em alguma cena ou em um personagem). A platéia são os observadores participantes do drama. E o espaço cênico um local para a ação, onde a vivência terapêutica ocorre.

Tecnicamente, o diretor segue as etapas propostas por Moreno $(1974,1975)$ para que todos se mobilizem e participem do Sociodrama: 1) Aquecimento: preparação dos membros do grupo para o evento, em que o diretor pode usar diversos recursos, como exposição oral, música, textos relacionados ao tema a ser abordado, para mobilizar os sujeitos a participarem das polêmicas e conflitos que forem emergindo no encontro; 2) Dramatização: aprofundamento ou vivência do tema/problema por meio de cenas ou personagens vividos pelos membros do grupo no espaço cênico, sendo que também pode ocorrer uma intervenção específica para um confronto sociométrico construtivo em relação ao tema ou às interações que surgem no evento. $\mathrm{O}$ diretor coordena o grupo com técnicas de ação, visando a manifestação da maioria sobre o tema protagônico, ou contribui para que o protagonista 
expresse o sofrimento grupal; 3) Comentários: fase de compartilhamento de sentimentos e de identificações com as problemáticas tratadas. $\mathrm{O}$ diretor busca uma reflexão, por parte de todos, do que aconteceu no sociodrama; 4) Processamento teórico: momento em que a unidade funcional equipe formada pelos diretor e egos auxiliares - fazem uma análise das ações ocorridas no evento ou uma análise sócio-cultural do momento do grupo.

Durante a etapa da dramatização, existem algumas técnicas que podem ser usadas pelo diretor do Sociodrama, advindas do Teatro Espontâneo e do Psicodrama, dentre elas, a do duplo: o diretor (ou ego auxiliar) expressa o que os membros do grupo não conseguem fazê-lo; a do espelho: o diretor (ou egoauxiliar) mostra fisicamente como o grupo está em relação ao tema, ou como a cena ocorre, para que o grupo se observe; e a da inversão de papéis: em que o diretor solicita uma troca de papéis, pedindo para que aquele que está num papel numa cena inverta de lugar, sinta e se comporte como o papel complementar (Moreno, 1975). As técnicas são usadas quando há bloqueios no grupo para a resolução ou aprofundamento dos conflitos e objetivam contribuir para a co-criação.

No método sociodramático há os seguintes princípios fundamentais (Moreno, 1975): todos os estímulos do presente contribuem para a criação imediata, pois passado e futuro se encontram na produção atual; o processo é experimental e pioneiro para tornar a pesquisa ativa e profunda; a livre atuação complementa a associação de palavras e o espaço tridimensional, em qualquer ambiente, concretiza as vivências interiores. Esses princípios se coadunam com a epistemologia histórico-estrutural (Demo, 2000) que busca no aspecto dinâmico o que há de padronizado, mas, ao mesmo tempo, tenta captar o máximo de sua fluência e das mudanças na identidade.

\section{Sociodrama e pesquisa qualitativa}

As informações colhidas pelo Sociodrama advém de: 1) de variáveis sociométricas, por exemplo, modo de constituição de grupos e subgrupos; 2) da sociodinâmica, apontada nos sentimentos e falas presentes na ação dos participantes em relação à polêmica; 3) dos tipos de cenas, personagens e conflitos; 4) da atuação do(s) protagonista(s) e 5) da participação dos membros do grupo no compartilhamento final. As análises desses dados desvelam os estados co-conscientes e co-inconscientes do grupo (Moreno, 1974). A análise sociodramática é uma leitura socionômica dos fenômenos grupais, que considera: a história da constituição do grupo; a atuação dos agentes do Psicodrama: diretor, egos, unidade, protagonista, platéia; a escolha do protagonista, os personagens e temas protagônicos; as hipóteses terapêuticas relacionadas aos temas protagônicos; as fases da sessão (aquecimento e sua manutenção, dramatização, compartilhamento); o procedimento e as técnicas usadas no método sociodramático; os tipos de direção; o encadeamento das etapas do Psicodrama e suas hipóteses; a sociometria (co-criação); variáveis sociométricas; as fases do grupo; as suas configurações; seu momento e clima afetivo; a sociodinâmica: variáveis sociodinâmicas - papéis sociais/culturais versus papéis latentes - e suas funções; os vínculos internos versus externos; o clima afetivo do grupo e nível do compartilhar; a análise social - momento do grupo versus da sociedade. Todos estes fatores pertencentes à análise sociodramática se relacionam com a construção conjunta do saber produzido durante a pesquisa interventiva.

\section{As questões metodológicas do Sociodrama}

Günther (2006), em artigo que traça paralelos entre a pesquisa quantitativa e a qualitativa, aponta que o comportamento deve ser compreendido em ambiente real, ou diante de condições artificiais ou de questionamento sobre a própria subjetividade do informante. A partir desta observação, pensa-se sobre a metodologia do psicodrama/sociodrama, como um momento em que estas três condições parecem ser reunidas numa mesma ocasião. $\mathrm{O}$ diretor de cena pode obter informações sobre estes aspectos, de forma aproximada, através do "como se" dramático. Mas, por se tratar de pesquisa em que o rigor deve ser enfatizado, o diretor/pesquisador necessita adotar procedimentos de planejamento e condições de registro que sejam favoráveis à captação de todos os detalhes que compõem a cena dramática. A ação tem uma carga grande e atualizada de espontaneidade. Pergunta-se como então conjugar este princípio com a necessidade de planejamento. 
A coleta das informações e a análise dos resultados do Sociodrama são deveras trabalhosas, pois, na tentativa de serem captados os significados presentes nas interações e a dinâmica interacional, usam-se filmadoras, gravadores e o registro do evento realizado pela unidade funcional. Com relação ao registro, a experiência mostra que este aspecto apresenta-se bastante dispendioso, pois é necessário que envolva gravação em filme. Os detalhes da ação dramática, sua intensidade, rapidez, a presença de muitos atores em cena, contracenando em troca de papéis, tudo regido pela permissão e mesmo incentivo para a espontaneidade, tornam-se pontos de difícil controle pelo pesquisador. Daí a necessidade de contar com a maior confiabilidade que o filme traz, pois mesmo com vários observadores descrevendo a cena, as demandas que a filmagem responde bem não são supridas.

Isto traz ainda a questão da presença de observadores na cena dramática. Qual o limite do seu papel? Como se manter nele diante de expressões dramáticas que envolvem emocionalmente a todos os que estão presentes? O papel de observador, na metodologia sociodramática, extrapola os limites da almejada neutralidade científica, tendo em vista que ele está comprometido com o social e é cúmplice dessa co-existência. Ao contrário de tentar exorcisar a subjetividade infiltrada, nas pesquisas sociodramáticas ela é altamente apreciada por seu valor heurístico. O filtro da subjetividade do observador traz uma riqueza de dados colorida pela experiência de ser tocado afetiva e cognitivamente pelas trocas do co-consciente e co-inconsciente grupal. Da mesma forma, a platéia não é absolutamente um elemento passivo na realização de sociodramas, por mais que sua postura possa refletir tal atitude.

\section{A dimensão interpretativa no Sociodrama}

Demo (1998) aponta que a pesquisa qualitativa se distingue pela preocupação em destacar a qualidade do objeto estudado, e que esta qualidade se apresenta na forma e no conteúdo. Assim, Costa (2004), ao analisar os resultados de sua pesquisa com a aplicação de método psicodramático, encontrou categorias provenientes de interpretação de um grupo multifamiliar que se expressou pelos diálogos e dramatizações: a análise temática, a relação entre as mães, entre estas e a equipe, a expressão de afetividade, a de espontaneidade, o ambiente lúdico e a presença da pesquisadora. A interpretação de falas associadas à das imagens, retiradas da ação dramática, amplifica e enriquece a compreensão da qualidade acima aludida.

Com relação à importância da análise de imagens pode-se citar, no campo da Psicologia Social, Passarelli (2000) que indica o cinema como uma linguagem cinematográfica capaz de explicitar temas de ordem social e que envolvem a subjetividade de vários sujeitos em seu processo, construindo enunciados desde a forma, a concepção artística até a relação com o espectador e a crítica. Rose (2002) chama a atenção para o fato de que na interpretação de imagens em movimento há sempre um aspecto de "translado" a ser considerado. A autora se refere a decisões que o interpretador deve tomar na sua tarefa, como privilegiar ou não os silêncios, as hesitações e toda a complexidade de detalhes presentes na infinidade de movimentos que compõem a dinâmica da imagem em ação. Estas decisões acabam por envolver a subjetividade do interpretador, na medida em que ele terá que escolher e rejeitar alguns destes detalhes, o que provavelmente fará com base em sua experiência.

Em sua proposta teórico metodológica Thompson (2000) apresenta a Hermenêutica de Profundidade (HP) como um referencial para a interpretação da realidade que abarca os aspectos sócio-históricos que indicam "as condições sociais e históricas de produção, circulação e recepção das formas simbólicas" (p. 366). Quando se faz a interpretação de uma ação dramática, esta é situada, sempre, em um contexto de tempo e de pertencimento a um grupo social, e compreende não só o "como se" psicodramático de Moreno (1975), mas também as condições históricas e atualizadas dele. Em outra fase da análise da HP, há a consideração da interpretação que é chamada de análise formal ou discursiva: "Formas simbólicas são os produtos de ações situadas que estão baseadas em regras, recursos, disponíveis ao produtor; mas elas são também algo mais, pois são construções simbólicas complexas, através das quais algo é expresso ou dito" (Thompson, 2000, p. 
369). A análise formal envolve tudo que é dito, e no seu formato com palavras e imagens, considerando que se trata de comunicação.

Rasera e Japur (2001) tratam das influências que o pensamento construcionista traz para a produção do conhecimento; na sua opinião é da interação entre pessoas, das respostas mútuas nela ocorridas que decorre a produção do conhecimento, e dele em Psicologia. O foco muda da dinâmica individual para a relacional, e no que se pretende demonstrar, para a grupal. Os autores explicitam o processo de análise da dinâmica grupal focalizando o registro das falas, da sua sequiência, dos eixos processual e temático nelas contidos e nas interações dos sujeitos, buscando a construção dos sentidos presentes nas interações. O rigor de descrição neste texto mostra a dificuldade que está inserida na análise das informações obtidas pelo método dramático: as falas, as histórias narradas, a sequiência do drama, as interações entre personagens, as interações entre equipe profissional e demais componentes do grupo, as interações ocorridas no grupo fora da "encarnação dramática", as relações entre o "como se" e a realidade grupal e social. Estes aspectos mostram a riqueza que esta análise pode proporcionar, mas, há um investimento de tempo para o cumprimento destes itens, para o rigor e atenção, visando evitar a armadilha de uma análise superficial e empobrecida.

Exemplo de uma análise sociodramática Estudo sobre a afetividade presente nas relações entre estudantes universitários que ingressaram no vestibular pela cota de inclusão social (cota de negros) e estudantes que ingressaram através do regime universal de vestibular.

Sociodrama - com cinco estudantes representantes de ambas as condições de ingresso no vestibular, quatro do sexo masculino e uma do sexo feminino, com média de idade de 20 anos; um diretor de cena, um ego auxiliar e dois observadores (estudantes de Psicologia), sendo o Sociodrama gravado em vídeo e registrado em audio por dois gravadores. Feita a transcrição de todas as fitas, o material impresso com cerca de 50 páginas. Primeiro passo: exaustiva leitura do material, elencando categorias: interação entre os participantes, entre eles e a unidade funcional, ação de protagonistas, análise das cenas dramáticas, interação entre os componentes da unidade funcional, movimentação corporal dos participantes.

\section{Considerações Finais}

Atualmente, os diversos âmbitos das ciências humanas e da saúde têm demandado por métodos e técnicas que respondam às necessidades de conhecer e abordar fenômenos cujo marco é o grupo. A proliferação do uso de técnicas sociátricas se estende aos mais diversos âmbitos do conhecimento, realidades sociais e contextos institucionais, o que se vê refletido no crescente número de artigos que vêm sendo produzidos com metodologias socionômicas no contexto da saúde, principalmente no que tange os aspectos pedagógicos e preventivos (Barros \& cols., 2001; Déa, Santos, Itakura \& Olic, 2004; González \& cols., 1998; Gual, 1999; L'Abbate, 1994; RamosCerqueira \& cols., 2005; Saar, 2005; Suárez \& Reyes, 2000).

Não é surpreendente que, de modo cada vez mais crescente, profissionais de diversas áreas do conhecimento recorram a métodos sociodramáticos para responder a questões de pesquisa ou que utilizem desta ferramenta para intervir em contextos grupais, razão de se discutir o sociodrama como método de pesquisa, traçar suas contribuições no âmbito da investigação e ensejar reflexões que subsidiem os profissionais que trabalham com grupos; pois há uma ampliação do olhar sobre a sua micro-realidade social para um socionômico que considera a complexidade embutida nas intrincadas redes de relacionamentos afetivos e libera o seu potencial espontâneo e cocriador facilitador da superação de crises.

\section{Referências}

Barbier, R. (2002). A pesquisa-ação. (L. Didio, Trad.). Brasília: Plano. (Original publicado em s/d).

Barros, T., Barreto, D., Pérez, F., Santander, R., Yépez, E, Abad-Franch, F., \& Aguilar, M. (2001). Un modelo de prevención primaria de las enfermedades de transmisión sexual y del VIH/sida en adolescentes. Revista Panamericana de Salud Pública, 10 (9), 84-94.

Cesarino, A. C. (2002). Psicodramana rua. Disponível em: $<$ http//www.psicodramadacidade.com.br/ cesarino.htm>. Acesso em 30 de novembro de 2003. 
Conceição, M. I. G. (1994). Estudo Sociométrico de uma Instituição Alternativa Elementos para a Construção de um Modelo de Atendimento a Meninos de Rua. Dissertação de Mestrado, Universidade de Brasília, Brasília.

Conceição, M. I. G., \& Sudbrack, M. F. O. (2004). Estudo sociométrico de uma instituição alternativa para crianças e adolescentes em situação de rua: construindo uma proposta pedagógica. Psicologia: Reflexão e Crítica, 17(2), 277-286.

Conceição, M. I. G., Tomasello, F., \& Pereira, S. E. N. (2003). Oficinas temáticas para adolescentes em medida socioeducativa: construindo um projeto de vida. Em M. F. O. Sudbrack, M. I. G. Conceição, E. M. F. Seidl, \& M. T. Silva (Orgs.), Adolescentes e drogas no contexto da justiça (pp. 203-214). Brasília: Plano.

Costa, L. F. (1998). Reuniões Multifamiliares: Uma proposta de intervenção em Psicologia Clínica na Comunidade. Tese de Doutorado, Universidade de São Paulo, São Paulo.

Costa, L. F. (2003). E quando acaba em malmequer? Reflexões acerca do grupo muiltifamiliar e da visita domiciliar como instrumento da Psicologia Clínica Comunitária. Brasília: Universa.

Costa, L. F. (2004). Grupos multifamiliares: construindo uma metodologia para a psicologia clínica na comunidade. Em M. A. Ribeiro \& L. F. Costa (Orgs.), Família e problemas na contemporaneidade: reflexões e intervenções do Grupo Socius (pp. 123-156). Brasília: Universa.

Costa, L. F., Penso, M. A., \& Almeida, T. M. C. (2004). Intervenções Psicossociais a partir da Justiça: Garantia de Direitos Humanos para Crianças e Adolescentes Vítimas de Violência Sexual. Em G. Maluschke, J. S. N. F. Bucher-Maluschke \& K. Hermans (Orgs.), Direitos Humanos e Violência (pp.259-272). Fortaleza: Fundação Konrad Adenauer/ UNIFOR.

Costa, L. F., Penso, M. A., Legnani, V., \& Antunes, C. (2005). O grupo multifamiliar com famílias de crianças e adolescentes vítimas de abuso sexual no contexto da crise. Em L. F. Costa \& T. M. C. Almeida (Orgs.), Violência no cotidiano: do risco à proteção (pp. 87-105). Brasília: Líber/ Universa.

Dea, H. R. F. D., Santos, E. N., Itakura, E., \& Olic, T. B. (2004). A inserção do psicólogo no trabalho de prevenção ao abuso de álcool e outras drogas. Psicologia Ciência e Profissão, 24(1), 108-115.

Demo, P. (1998). Pesquisa qualitativa. Busca de equilíbrio entre forma e conteúdo. Revista Latino Americana de Enfermagem, 6(2), 89-104.

Demo, P. (1999). Conhecimento moderno. Sobre ética e intervenção do conhecimento. Petrópolis: Vozes.

Demo, P. (2000). Metodologia do conhecimento científico. São Paulo: Atlas.

Franco, M. A. S. (2005). Pedagogia da Pesquisa-Ação. Educação e Pesquisa, 31(3), 483502.

González, M. L. L., Fuentes, A. C., Puente, P. H., Gallo, S. P., Carral, M. F., Thomas, H., Douglas, J., Markham, W., Charlton, A., Vries, H., Leijs, I., Mesters, I., \& Ausems, M. (1998). Intervención educativa escolar para prevenir el tabaquismo: evaluación del proceso. Revista Española de Salud Publica, 72(4), 303-318.

Gual, J. M. (1999). La enseñanza de la ética moderna. Revista Cubana de Salud Pública, 25(2), 166-177.

Günther, H. (2006). Pesquisa qualitativa versus pesquisa quantitativa: esta é a questão? Psicologia: Teoria e Pesquisa, 22(2), 201-209.

Kellerman, P. F. (1998). Sociodrama. Revista Brasileira de Psicodrama, 6(2), 51- 68.

L'Abbate, S. (1994). Educação em saúde: uma nova abordagem. Cadernos de Saúde Pública, 10(4), 505-510.

Marra, M. M. (2003). De “Bombeiro” à Multiplicador: Abordagem Socio-dramática à Família no Contexto do Conselho Tutelar. Dissertação de Mestrado, Universidade Católica de Brasília, Brasília.

Marra, M. M., \& Costa, L.F. (2004a). A pesquisa-ação e o Sociodrama: Uma conexão possível? Revista Brasileira de Psicodrama, 12 (01), 99-116. 
Marra, M. M., \& Costa, L. F. (2004b). O Psicodrama como proposta teórico metodológica para a comunidade. Família e Comunidade, 1(1), 15-38.

Menegazzo, C. M., Tomasini, M. A., \& Zuretti, M. M. (1995). Dicionário de Psicodrama $e$ Sociodrama. (M. Lopes, M. Carbajal \& V. Caputo, Trads.).São Paulo: Agora (original publicado em 1992).

Moreno, J. L. (1974). Psicoterapia de Grupo e Psicodrama. (A.C.M. Cesarino Filho, Trad.). São Paulo: Mestre Jou. (Original publicado em 1959).

Moreno, J. L. (1975). Psicodrama. (A. Cabral, Trad.). São Paulo: Cultrix. (Original publicado em s/d).

Nery, M. P., \& Conceição, M. I. G. (2005). Sociodrama e política de cotas para negros: um método de intervenção psicológica em temas sociais. Psicologia Ciência e Profissão, 25(1), 132-145.

Nery, M. P., \& Conceição, M. I. G. (2006). Sociodrama da inclusão racial: quebrando a inércia. Revista Brasileira de Psicodrama, 14 (1), 105-119.

Passarelli, C. A. F. (2000). Imagens em diálogo: filmes que marcaram nossas vidas. Em M. J. Spink (Org.), Práticas discursivas e produção de sentidos no cotidiano. Aproximações teóricas e metodológicas. (pp. 273-283). São Paulo: Cortez.

Penso, M. A., Gusmão, M. M., \& Ramos, M. E. C. (2003). Oficina de idéias: uma experiência precursora com adolescentes em conflito com a lei pelo envolvimento com drogas. Em M. F. O. Sudbrack, M. I. G. Conceição, E. M. F. Seidl, \& M. T. Silva (Orgs.), Adolescentes e drogas no contexto da justiça (pp. 191-201). Brasília: Plano.

Polejack, L., \& Costa, L. F. (2003). AIDS, Psicodrama e Conjugalidade: compondo a diferença. Revista Brasileira de Psicodrama, 11(1), 43-63

Ramos, M. E. C., Costa, L. F., Marra, M. M., \& Monteiro, A. (1998). O psicodrama como metodologia de intervenção no trabalho comunitário. Revista Brasileira de Psicodrama, 6(1), 11-123.

Ramos-Cerqueira, A. T. A., Lima, M. C. P., Torre, A. R., Reis, J. R. T., \& Fonseca, N. M. V. (2005). Era uma vez... contos de fadas e psicodrama auxiliando alunos na conclusão do curso médico. Interface-Comunicação, Saúde, Educação, 16 (9), 81-90.

Rasera, E. F., \& Japur, M. (2001). Contribuições do Pensamento Construcionista para o estudo da Prática Grupal. Psicologia: Reflexão e Crítica, 14(1), 201-209.

Rose, D. (2002). Análise de imagens em movimento. Em M. W. Bauer, \& G. Gaskell (Orgs.), Pesquisa qualitativa com texto, imagem e som. Um manual prático. (P. Guareschi, Trad.) (pp. 343-364). Petrópolis: Vozes. (Original Publicado em 2000).

Saar, S. R. C. (2005). Especificidade do enfermeiro: uma visão multiprofissional. Tese de Doutorado, Universidade de São Paulo, Ribeirão Preto.

Scaffi, N. (2002). Socionomia na prevenção da AIDS entre indígenas. Revista Brasileira de Psicodrama, 10(1), 13-30.

Seixas, M. R. D. (1992). Sociodrama Familiar Sistêmico. São Paulo: ALEPH.

Suárez, L. E., \& Reyes, W. G. (2000). Las terapias con recursos artísticos. Su utilidad en la atención primaria de salud. Revista Cubana Medicina General Integral, 16(3), 295-304.

Thompson, J. B. (2000). Ideologia e cultura moderna: teoria social crítica na era dos meios de comunicação de massa. (Grupo de Estudos sobre ideologia, comunicação e representações sociais da pós-graduação do Instituto de Psicologia da PUCRS). Petrópolis: Vozes. ( Trabalho original publicado em 1995).

Zampiere, A. M. F. (1996). O Sociodrama Construtivista da Aids - Método de construção grupal na educação preventiva da Síndrome de Imunodeficiência Adquirida. São Paulo: Psy.

Este texto refere-se a discussões sobre metodologia do trabalho de doutoramento do primeiro autor. 